\title{
Acaso x programação o processo criador e a máquina
}

Ana Salles Mariano*

* Professora do Departamento de Arte da Faculdade de Comunicação e Filosofia da PUC-SP. 
Ítalo Calvino, em uma de suas obras mais interessantes, nos apresenta Palomar a tentar observar uma onda que chega na praia Seu esforço em focalizar o objeto é obsessivo, mas não consegue livrar-se das outras ondas que impedem a pureza da visão. Como descrever a onda, eliminada as interferências contextuais? É sempre de um ponto de vista mais ou menos relativo que observamos um fenômeno e, se a pretensa objetividade foi tão cara à Ciência durante muito tempo, hoje a consciência de seus limites nos permite ter mais informação sobre um fato quando consideramos que toda análise é reveladora de um fenômeno e, ao mesmo tempo, de um certo modo de vê-lo, modo este que traz um tempo, um recorte ideológico, um dado espaço conceitual.

A consideração da arte em seu processo de criação implica em um posicionamento frente aos conceitos de produção, de trabalho, de ação, de instrumento. Por isso mesmo, no final do século $X X$, em plena era da informática, os estudos de criação não podem deixar de fazer referência às novas formas de produção. Como em outros momentos da História, temos também agora os apocalípticos e os integrados, ou melhor dizendo, os que negam valor estético a tudo que for produzido com a interferência do computador e os que consideram as novas técnicas como possibilidades produtivas.

É nosso objetivo, examinar duas posições divergentes para caracterizar os fundamentos conceituais implícitos. De um lado as idéias apresentadas por Fayga Ostrower em Acasos e Criação Poética. De outro os conceitos propostos pelo poeta, crítico e também professor Melo e Castro, principalmente em seu livro Algorritmos: infopoemas; nos artigos "Uma transpoética 3D" e "Síntese Genética" e em seus depoimentos sobre a interferência do computador no processo de criação. 
Vamos procurar exemplificar as colocações através da análise de um de seus processos poéticos - FR ACTA - aqui publicado às páginas 75 à 81.

As citações serão remetidas a F. O. (Fayga O strower) e M.C. (M elo e Castro), para simplificar as referências, devidamente localizadas na bibliografia.

Seguindo a trilha de suas obras anteriores: Uni versos da Artee Criati vi dade e Processos de Criação, Fayga Ostrower continua em Acasos e Criação Poética a formular questões importantes relativas à arte, sempre do ponto de vista de uma artista que é também professora e estudiosa os problemas que emergem de seus ofícios e de sua própria vida. Este fato - da ligação da arte com a vida, do fazer artístico como expressão de sensibilidade - é sempre reafirmado, valorizando o percurso da criação como um processo de conhecimento e, principalmente, de auto-conhecimento. Fica explícita a condução subjetiva que dará às diversas questões analisadas enquanto percussão e repercussão em sua própria vida.

O capítulo inicial é dedicado ao acaso, que dá título à obra e cuja discussão traz considerações importantes com referência ao conceito de arte. $O$ acaso é tratado como expectativa latente, ou melhor, como mobilização psíquica, uma receptividade do ser em relação aos estímulos, uma percepção sagaz da interligação de circunstâncias que iluminam os processos de criação (seja de arte, de ciência ou de vida). É esta percepção do acaso que a autora identifica com inspiração: momento de elevada intensidade espiritual, de revelação de analogias, de intuição, de apreensão de um sentido mais claro da realidade, mas também um momento místico e de profunda mobilização para as profundezas do eu. Portanto, inspiração está indissoluvelmente ligada à individualidade.

E m algumas abordagens psicanalíticas, o momento de percepção do acaso, ou insight, é passivo, resultante de articulações ou de reflexos de traumas da infância. F.O. discorda dessa posição mostrando o acaso como momento ativo de descida aos estratos mais profundos da psiquê de onde se volta abastecido. Daí ela considerar: acaso - insight - inspiração como facetas de um mesmo fenômeno de percepção.

A percepção é um processo dinâmico, estruturado através de procedimentos seletivos (prioridades intuitivas), que nos levam a estabelecer conexões, a buscar padrões de coerência e a estabelecer situações globais de referência. Os princípios fundamentais de estruturação da percepção - vistos aqui em acordo com as teorias da G estalt - são semelhantes aos da criação artística. F.O. ilustra com vários exemplos a relação parte/todo e a relatividade decorrente da variação da identidade das formas e do significado. O que é parte? O que é todo? O que dá 
configuração a uma forma? O que é configurado? Ora um elemento é continente, ora outro o contém. A teoria do campo de percepção evidencia a dinâmica do processo perceptivo e o torna comparável ao processo de criação da obra de arte. E stas correlações funcionais que constituem o percurso criador formam o estilo. O caráter expressivo inerente às formas da linguagem artística é decorrente das escolhas básicas que vão marcando a obra durante o processo de elaboração. As formas simbólicas objetivam vivências subjetivas.

É importante observar que "acaso" está em oposição a "programação". A programação determinaria a condução do processo e portanto impediria o acaso, o insight, a inspiração e consequentemente a expressão. Em verdade, o que aqui se coloca é o

temor ancestral de que o eu humano possa ser substituído pelo eu de uma máquina, o que contém um ranço ontológico ainda corrente, mas inadequado para se considerar os problemas presentes.( M. C.)

Além da limitação colocada à subjetividade, o uso do computador implicaria, para F.O., em alteração no caráter comunicativo da obra. A simbolização é um processo formador, conscientizador e comunicador. Portanto não é possível considerar a função expressiva da linguagem independente da função comunicativa. Toda obra de arte, considerando seu caráter comunicativo, deverá ter uma dimensão social. O estético deve encerrar o ético. As linguagens artísticas pertencem ao acervo cultural. Tomando a dimensão social como critério, F.O. traça um percurso histórico da relação arte e público: mostra a cisão que vai ocorrer a partir do R omantismo pela ênfase no individual, analisa as vanguardas e as rejeita em sua maior parte pela incomunicabilidade, pelo vazio de sentimentos e por sua incapacidade de revelação espiritual.

Estes conceitos, trabalhados na análise de várias obras, vão montando para o leitor a visão da autora e, portanto, não causará surpresa sua abordagem da arte nas novas tecnologias. F.O. analisa a obra de arte pós revolução industrial dentro da esteira lógica: industrialização ${ }^{\circledR}$ sociedade de consumo ${ }^{\circledR}$ mecanização $\circledast$ desumanização

Essa abordagem se apoia no fato das sociedades industriais separarem o trabalho e a arte, criando a oposição ação útil X ação inútil. Além disso, o desenvolvimento das linhas de montagem desvinculam o sujeito produtor, do objeto produzido e impedem a percepção do processo. As tecnologias geram produtos que não passam de mera demonstração tecnológica e onde não é possível incorporar a expressividade artística. “O ótico não é ético nem estético necessariamente." 
Para justificar tais afirmativas, a autora recorre a distinção "homem $\mathrm{X}$ animal" e "homem X máquina". Diferentemente do animal, o homem é capaz de escoIher o padrão de referência para a construção do significado de uma mensagem. Diferentemente da máquina, o homem percebe o sentido das coisas e nele os sentidos criam ressonâncias afetivas, instauram ordenações significativas. Os modelos de computação são programados segundo cadeias lógicas e operam a partir de símbolos abstratos organizados por regras explícitas. O computador simula reconhecimentos semânticos e avaliações, mas o computador não pode perceber.

Dessa forma, as produções da "computer-art" são vistas como catálogo i lustrado de demonstração técnica da máqui na. Sofisticadas na tecnologia, mas vazias de emoção. Para a produção da arte é preciso expressividade - transposição de vivências e valores para os termos de uma linguagem e isto é impossível, dentro da lógica estabelecida por F.O., quando se considera a linguagem da máquina. As imagens assim produzidas representam equações matemáticas, não emoções.

As vivências, os valores, que garantem a expressividade estariam ausentes já que o autor, a seu ver, não determina o momento de dar por concluída sua obra. As hesitações, as escolhas, as idas e vindas, as delimitações e ampliações não previstas inicialmente, as descobertas que alteram o percurso evidenciam que a obra não é programável como o é a linguagem do computador. Portanto, a obra produzida no computador tem sua finalização prevista e realizada pela máquina, na visão de F. O..

Esta conclusão parte de premissas falsas. Os programas - diferente do que parece supor a autora - oferecem possibilidades de construção e não determinam caminhos fechados, nem o hardware é uma caixa mágica a operar sem interferência do homem que continua sendo o sujeito operante. A diferença de instrumento dará, com certeza, outra dinâmica ao processo e ao produto, mas não é a máquina que seleciona, que dirige, a despeito de quem a opera. Se a escolha do programa implica em possibilidades pré-determinadas enquanto processamento da informação, por outro lado há que se considerar a matriz de onde se parte e as combinatórias escolhidas. Q uase sempre a mesma obra é processada em vários softwares e esta combinação de interferências é projetada pelo autor. A análise de um exemplo deve ser elucidativa. O poema teve suas etapas numeradas, para possibilitar a referência. Na margem direita indicamos a prancha a que nos referimos.

E m FRACTA, o poeta toma como matriz um poema produzido na década de 60 , que obed ecia a uma estrutura fragmentar, de versos curtos e imagens visuais e o submete inicialmente aos recursos tipográficos. Opta por um tipo vazado - terri tório do branco - coerente com o próprio texto: a configuração visual está integrada ao sentido e a escolha da letra não é determinada, mas possibilitada pelo computador que nos oferece escolhas antes só possíveis num custoso trabalho de 
composição. Hoje, um simples editor de texto pode oferecer uma variedade incrível de tipos a depender da quantidade de fontes instaladas. Com apenas um CD, instala-se cerca de 5.000 fontes diferentes. Portanto, já nos recursos básicos, há a interferência do ser humano que dotou sua máquina de maiores ou menores possibilidades. A mplia-se o universo de escolhas. A experimentação é quase infinita e a velocidade com que se opera permite múltiplas tentativas. Sem projeto significante esse processo seria um caos. E o projeto significante está na proposta do autor e não no software.

Esse projeto vai recebendo interferências das descobertas, dos acasos. É comum que o artista imprima várias tentativas para melhor analisá-las e até mesmo experimente diferentes suportes. Neste caso o autor-leitor poderá observar três realizações possíveis: na tela, no papel, no acetato: "folha singular na finura do a ar". Qual das hipóteses realiza melhor o significado? Ou, talvez, que novos jogos significantes elas instauram?

O deslocamento da transparência sobreposta ao papel já impresso cria possibilidades. As folhas soltas permitiriam a exploração da sobreposição, como ocorreu ao poeta. Acaso. O jogo entre as páginas gera um novo percurso: trabalhar com as sobreposições. Aumenta a complexidade do texto e palavras se destacam sugerindo nova geografia.

A diagramação fratura (FR ACTA) o texto, enfatiza signos em meio ao ruído circundante, cria realações significantes a partir de paralelos visuais: "Iingua complexa/máquina, diz/expressa, espesso/finura, líquido/território." Faz com que a percepção encontre relações inusitadas, como em esfera plana.. Momentos ricos em descobertas. Insight.

Conforme depoimento do autor, as subsequentes interferências na legibilidade do texto vão sendo sugeridas pelas sobreposições sucessivas. Sobre( $\mathrm{im}$ ) posi ção: repetição do texto reduzido no quadrante superior esquerdo e no quadrante inferior direito. R uído. A parte contém o todo. O todo está na parte. FRACTA - fractais. As contínuas descobertas ampliam o sentido do texto.

Não estaríamos observando aqui a dinâmica do processo perceptivo e de construção artística, conforme as consideraçõe de F. O. ? As escolhas básicas vão marcando a obra e gerando as transformações. O homem percebe o sentido e as ressonâncias reverberam em novas ordenações significativas que ele projeta e a máquina executa.

Relemos o poema, redescobrimos seus significados na possibilidade do signo discreto, digital, criar o analógico, ou seja, o estilhaçamento evidencia o caráter discreto, digital do signo verbal - para com ele criar a analogia. A palavra é território, continente, capaz de conter o mar, o céu, a terra, o espesso na finura. 
A oposição analógico/digital, não procede quando consideramos a questão literária, já que a função poética é exatamente a recuperação do analógico no discreto. De acordo com F. O., do digital não se chega ao analógico. A linguagem digital é linear, lógica, precisa, em oposição à linguagem analógica.

O uso do alfabeto, a imposição da lógica linear na construção da escrita e o advento do método racional de interpretação criaram o "boné de pensar" do ocidente. No entanto, a construção literária vai ser sempre uma ruptura nesta órdem. A noção de hipertextualidade está presente na matriz literária e a polissemia, a ambiguidade, os efeitos de sentido, a metáfora, enfim a projeção do paradigma sobre o sintagma vai caracterizar o advento do analógico a partir das unidades discretas que constituem a lingua. O poema em análise põe estes conceitos em evidência. A matriz do poema propõe significados para a lingua, que se materializam na construção.

O texto é cada vez mais figura, materializada pelos filtros de diferentes softwares. O texto se desfaz. A esfera se faz. Instantâneos de luz: a esfera plana explode visões. Ilegibilidade? A velocidade do efeito altera o resultado. O preto das letras transformado, diluído - líqui do gaz - no cinza da esfera semovente.

Composição em espelho. De um lado a imagem deformada, de outro a matriz verbal em sua forma quase inteira. N ovos filtros. As formas submetidas a transformação randômica adquirem elasticidade. O movimento ondular cria dobras, formas côncavas, convexas. I magem ótica inusitada para a linha reta da escrita. M over as transparências e imaginar outras alterações, movimentos ondulantes num processo de contínuo anamorfismo até a ilegibilidade total.

Turbulênci a sígnica. Catástrofe. $\mathrm{O}$ dito desfeito refeito... $\mathrm{Na}$ aparente perda de sentido, novos sentidos se instauram. A ilegibilidade é operacional pois instiga o leitor. A interatividade necessária desmente a incomuni cabilidade ou opaci dade, sugeridas por F.O.. Na verdade, o leitor é chamado a interferir. Opaci (vi) dade: estas obras só não se comunicam com o leitor passivo - se é que em arte podemos admitir tal leitor. A obra é writerly, ou seja, convoca à participação, à interferência, à escritura. Esta série poderia ser processada em rede e aí romper-se-ia mais claramente a cisão autor $X$ leitor.

Se retomarmos o poema-matriz depois do percurso realizado, qualquer comentário ficará redundante. Todo processo parece estar ali previsto. Intuição e rigor conduziram as experiências significantes. Complexa máquina na procura dos resultados. A palavra plana se esferiza e expande visões.

O exemplo é suficiente, a nosso ver, para que se dê conta da presença criadora e crítica da mente que conduz o processo. É ela e não a máquina que "escolhe o padrão de referência para a construção do significado" (F.O.). O sujeito criador não está desvinculado do processo produzido. 
A questão reside portanto nas características do software usado, isto é, se no seu quadro conceitual está contida ou não a liberdade probabilística e combinatória permitindo a intervenção criativa dos utilizadores. (M.C.)

Para finalizarmos a discussão destas idéias é necessário retomar o ponto de partida e ver o computador como instrumento, não como simulacro do homem. As formas simbólicas são construídas com uso de instrumentos - da pedra lascada ao computador - e não se pode inferir que eles constituam, por si só, a linguagem, embora eles interfiram na natureza da própria linguagem.

"A linguagem humana é complexa, capaz de associações livres, de analogias e de produção de metáforas", como afirma F. O. e o que realizamos no computador é linguagem humana, potencializada pela mobilidade transformativa dos pixels, como observa e realiza M. C..

O alfabeto que usamos há 25 séculos é um software de menos de 30 letras e, no entanto, a inventividade humana tem construído com ele lingüas diferentes, organizações estruturais complexas, mensagens de variação inimaginável.

A história das obras literárias é marcada pelo desenvolvimento da imprensa, que causa uma transformação significativa nos textos, não só por ampliar o seu alcance a diferentes leitores, mas por fixar formas para possibilitar a reprodução. A imprensa significou uma ruptura com o traço do autor e com certeza revolucionou as mensagens escritas, mas não se questiona a autoria de um texto, a sua capacidade expressiva, pelo fato de não trazer as marcas individuais de uma escrita (traço) pessoal, ou por distanciar o autor de seus leitores, nem mesmo por submeter o texto a um procedimento industrial.

O computador não é o criador nem o intérprete, ele é o meio que se oferece como operador de linguagens. Não se trata, sobretudo, de chamar de arte qualquer imagem, mas tão somente aquelas em que a tecnologia - como outra técnica qualquer - foi usada para a produção do efeito artístico. No entanto, como já afirmamos, estas considerações de F.O. estão perfeitamente coerentes com os conceitos que foram sendo desenvolvidos no percurso da obra e basicamente se fundamentam em uma visão metafísica da obra de arte.

Talvez pareça inconcebível tratar em uma vertente crítica não metafísica uma obra de arte que é cada vez mais caracterizada por sua imaterialidade ou por uma materialidade plástica, semovente, virtual. Tudo é luz. Da luz se faz a forma, a aparente materialidade das coisas. Mas é preciso ver que as novas mensagens

propõe uma nova síntese da percepção e do sentimento do mundo; de uma realidade virtual que contém reais virtualidades de transformação, não só da repre- 
sentação como da fruição estética e emocional desse mundo ele mesmo em transformação ambígua. (M. C.)

A info-arte está, portanto, absolutamente ligada a realidade de seu tempo, aos percursos do homem dotado de um novo sentir, de uma nova percepção e que desenvolveu tecnologias que implicam em novos procedimentos para agir sobre a linguagem, com a linguagem. E a pensar sobre ela e o mundo..

A questão reside na invenção desafiante que as alterações da percepção provocadas e sofridas pelo mesmo homem, isto é, por nós próprios e todos nós, hoje e agora, nos impele a realizar sempre mais complexas, mas também mais instigantes experiências, ao encontro do que ainda ontem era impossível, impensável e até insensível. ( M .e C.)

Os traços caracterizadores da info-poesia: a participação efetiva e interferente dos receptores que dilui a oposição autor/leitor e dá uma dimensão coletiva à produção; o fato da obra ser um processo contínuo porque cada etapa é matriz de novas transformações e a virtualidade das mensagem que permite sua realização em diferentes formas e até mesmo diferentes suportes - todas estas características modificam a ordem estabelecida na consideração do autor da obra e, consegüentemente de sua inserção no mercado. Como caracterizar a autoria? Como contextualizar a obra? Quais devem ser as leis dos direitos autorais? Como se dará a publicação das obras? Como serão organizadas as bibliotecas? E os museus?

Há mais perguntas que respostas, mas estas só serão possíveis se usarmos a luneta e não nos negarmos a ver. Norman T. White afirma que

Parte do problema está na própria palavra computador. O nome implica obstinação e resultados controlados. Seria muito melhor o chamarmos de "o espelho deformante da casa dos espelhos" (fun-house mirror), o que nos remete à capacidade que o computador tem de absorver nossa intenção e jogá-la de volta para nós como metamorfose surpreendente. Potencialmente esta metamorfose fornece uma ponte conceitual para um padrão completamente novo de pensamento e investigação

e esta ponte conceitual poderá enriquecer os trabalhos de pesquisa sobre os processos de criação.

Eis como uma ameaça pode ser transformada na abertura de novos e insuspeitados territórios para a invenção e a criatividade. (M . e C.). 
Para a crítica genética, o computador é um grande auxiliar ao possibilitar o registro das metamorfoses do processo, como queria Picasso, "oferecendo a possibilidade de descobrir o caminho seguido pelo cérebro na materialização do sonho".(Salles). Mas, é também um desafio, já que a transformação anamórfica é constitutiva do processo de criação da obra em contínua metamorfose. E o autor se transmuda em diversos operadores.

\section{Referências Bibliográficas}

CALVINO, Ítalo. Palomar. São Paulo: Companhia das Letras, 1992.

CASTRO, Ernesto Manuel de Melo e. Algorritmos: infopoemas. São Paulo: Musa Editora, 1998.

Uma transpoética 3D - In Dimensão - R evista Internacional de Poesia - A no XVIII, no 27, U beraba, M. G ., 1998.

Síntese Genética (inédito). São Paulo, 1998.

OSTR OWER, Fayga. Acasos e Criação Artística. 2a ed. Rio de J aneiro: Editora Campus, 1995.

SALLES, Cecília Almeida. Gesto Inacabado : processo de criação artística. São Paulo: Annablume, 1998.

WHITE, Norman T. A Casa dos Espelhos. In: DOMINGUES, Diana (org.) A arte no século XXI: a humanização das tecnologias. Sào Paulo: E dunesp, 1997. 



\section{outros \\ ensaios}
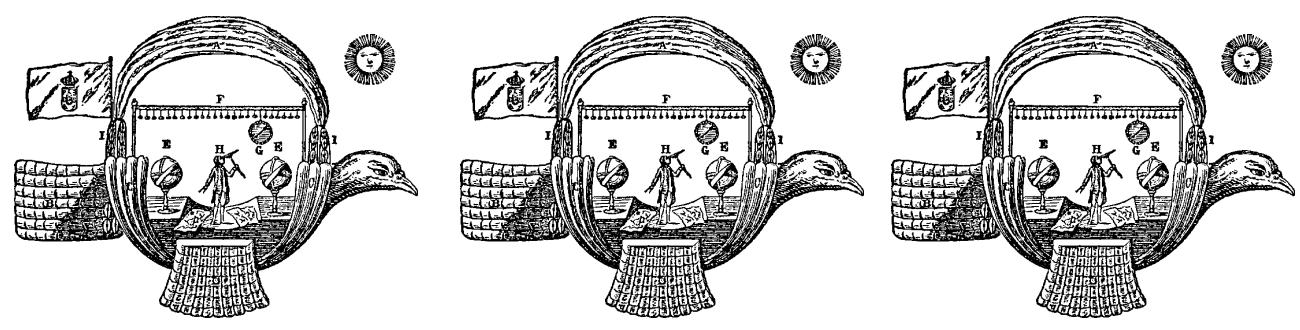